\title{
Transcutaneous Electrical Retinal Stimulation Therapy for Age-Related Macular Degeneration
}

\author{
Kei Shinoda ${ }^{1,2}$, Yutaka Imamura ${ }^{1}$, Sayaka Matsuda $^{1}$, Maiko Seki ${ }^{1}$, Atsuro Uchida ${ }^{1}$, \\ Terry Grossman ${ }^{3}$ and Kazuo Tsubota ${ }^{*}, 1$ \\ ${ }^{I}$ Department of Ophthalmology, Keio University School of Medicine, 35 Shinanomachi, Shinjuku-ku, Tokyo 160-8582, \\ Japan \\ ${ }^{2}$ Laboratory of Visual Physiology, National Institute of Sensory Organs, National Hospital Organization, Tokyo Medi- \\ cal Center, 2-5-1 Higashigaoka, Meguro-ku, Tokyo 152-8902, Japan \\ ${ }^{3}$ Frontier Medical Institute, 2801 Youngfield St - Suite 117, Golden, Colorado, 80401, USA
}

\begin{abstract}
This reports the preliminary outcome of a transpalpebral electrical retinal stimulation therapy for age-related macular degeneration (ARMD).

Twenty-one patients consisting of 16 with wet-type (Group-W) and 5 with dry-type (Group-D) ARMD with a mean age of $73.9 \pm 9.5$ years (range 51 to 85 years) were recruited for this study. Transpalpebral electrical retinal stimulation (20 minutes, $800 \mu \mathrm{A}$ ) was applied on the patients 4 times per day for up to 1 month. The mean best-corrected visual acuity (Early Treatment Diabetic Retinopathy Study [ETDRS] score) changed from 29.5 \pm 5.1 to $31.8 \pm 5.0$ in Group-W and from $39.8 \pm 4.7$ to $42.9 \pm 4.9$ in Group-D. Neither ocular nor systemic adverse effects were observed with the exception of one patient who developed contact dermatitis. Due to several limitations such as lack of control, patients' learning effect, etc, the efficacy of the therapy could not be drawn. This preliminary study, however, showed that the transpalpebral electrical retinal stimulation therapy can be non-invasively applied on wet-type ARMD patients.
\end{abstract}

\section{INTRODUCTION}

Age-related macular degeneration (ARMD) is a leading cause of blindness in industrialized countries, which affects primarily the choriocapillaris, Bruch's membrane, and the retinal pigment epithelium [1].

The exudative form, so-called wet type, is characterized by the development of choroidal neovascularization (CNV). Recently, photodynamic therapy or vitreous surgery is being successfully performed to restore vision but only in selected cases where photoreceptor degeneration is still fresh [2-7]. Recently, positive results of anti-vascular endothelial growth factor (VEGF) have accumulated [8,9], but the effect is limited in advanced stages. Furthermore, no effective treatment exists for eyes with geographic atrophy, drusen, and pigment alterations, so-called dry type. A growing volume of investigations have reported the keys to reveal the etiology, including the Age-related Eye Disease Study (AREDS), which provided a novel first step towards preventive medicine for the disease [10-14]. However, advanced damage cannot be restored. A polymorphism (Tyr402His) in the complement factor $\mathrm{H}(\mathrm{CFH})$ gene has recently been reported to increase the risk of AMD [15-17].

Recent reports have noted that electrical stimulation has neuroprotective potential by means of the enhancement of neurotrophic factors in several different neural tissues by

*Address correspondence to this author at the Department of Ophthalmology, Keio University School of Medicine, 35 Shinanomachi, Shinjuku-ku, Tokyo 160-8582, Japan; E-mail: tsubota@sc.itc.keio.ac.jp subretinal implants $[18,19]$. Although the exact mechanism has yet to be elucidated, several investigators have shown the upregulation of neurotrophins in the central and peripheral nervous system in relation to electrical stimulation [20-22]. Thus, applying electrical stimulation to the retina may induce a protective effect on the diseased retina through the activation of the endogenous neuroprotective agents. It is, however, difficult to stimulate the retina electrically in a routine clinical environment. The subretinal implants were reported to upregulate neurotrophic factors, resulting in a protective effect on the remaining retinal circuitry $[23,24]$. The drawback to this novel treatment is that surgery is required. Morimoto et al. [20] reported a less invasive way based on the finding that novel transcorneal electrical stimulation rescues retinal ganglion cells by activating endogenous retinal IGF-1 system, which has long been known to evoke light sensations or cortical potentials that stem from inner retinal neurons [25-28].

These findings prompted us to examine the feasibility of utilizing transpalpebral electrical retinal stimulation therapy on patients with wet-type ARMD.

\section{PATIENTS AND METHODS}

Twenty-seven eyes with wet-type ARMD (Group W) and 7 eyes with dry-type ARMD (Group D) were studied. The patients consisted of 15 males and 1 female, aged 51 to 85 years with a mean of $73.3 \pm 9.8$ years $( \pm$ SD) in Group W and 5 males, aged 63 to 85 years with a mean of $75.7 \pm 9.2$ years $( \pm \mathrm{SD})$ in Group D. The procedures used conformed to the tenets of the Declaration of Helsinki, and written informed consent was obtained from each individual who par- 
ticipated in this study after explanation of the procedures. This prospective interventional case study was approved by the Institutional Review Board of Keio University Hospital. Eyes with a wet-type or dry-type ARMD lesion were recruited for this study. The lesion had to involve the geometric center of the foveal avascular zone.

Patients were excluded if they had any significant ocular disease other than subfoveal CNV or geographic atrophy, which affected visual acuity, a history of intraocular or laser surgery within 6 months, or if they had taken any medication used for AMD such as vitamins or lutein in the 6 months prior to the examination. Patients whose condition met the criteria of photodynamic therapy (PDT) or antiVEGF therapy of intravitreal pegaptanib injection, which was ongoing as a clinical trial, were also excluded. Consequently consecutive patients were enrolled. Eyes with pathologic myopia, which was defined as an eye that requires a distance correction of at least -6.0 diopters or eyes with an axial length of more than $26.5 \mathrm{~mm}$, were also excluded.

A microcurrent of $800 \mu \mathrm{A}$ was transpalpebrally applied to both eyes by using a microcurrent stimulator (Fig. 1, Skylark Device \& Systems Co., Ltd., Taiwan). One session lasted for 20 minutes and was performed 4 times per day. The 20-minute protocol consisted of a monophasic pulse with a frequency of $290 \mathrm{~Hz}$ for 1 minute, $31 \mathrm{~Hz}$ for 2 minutes, $8.9 \mathrm{~Hz}$ for $10 \mathrm{~min}$ utes, and $0.28 \mathrm{~Hz}$ for 7 minutes. The transcorneal electrical stimulation was clinically applied using 300 to $2000 \mu \mathrm{A}$ of 20 $\mathrm{Hz}$ stimulation for 30 minutes with an interval of one month to the patients with optic neuropathy [29]. The details of the protocol for electrical retinal stimulation have not yet been established, and the protocol in the transpalpebral electrical stimulation is to be determined.

Best-corrected visual acuity testing, the Early Treatment Diabetic Retinopathy Study (ETDRS) score, slit-lamp examination, funduscopy, fluorescein angiography, and automated static visual field testing, were performed before and 4 weeks after the application of the daily microcurrent treatment. A masked examiner performed the visual acuity examinations. The results of Humphrey central 30-2 perimetry (Carl Zeiss Meditec, Dublin, CA) with more than 4 poor fixation (about $20 \%$ or more), more than 3 false positive data (33.3\% or more), or more than 3 false negative data (33.3\% or more) were excluded from the analysis. The mean deviation measured by Humphrey central 30-2 perimetry (Carl Zeiss Meditec, Dublin, $\mathrm{CA}$ ), which assesses the sensitivity distribution in the central retinal area, was used for statistical evaluation.

The patients were asked 4 weeks after the treatment to rate the subjective therapeutic effect as poor, fair, good, and very good. For analysis the result was converted to scores of $1,2,3$, and 4 as poor, fair, good, and very good, respectively.

For the statistical procedure, visual acuity of 'counting fingers' and 'hand motion' were assigned to $20 / 20000$ and $20 / 200000$, respectively, according to the previous report [30]. The paired t-test was performed to determine the changes of visual acuity and the mean deviation of the automated static perimetry.

\section{RESULTS}

All the patients reported phosphene when the microcurrent was provided. This can be interpreted that the retina was electrically stimulated. Best-corrected visual acuity before and 4 weeks after treatment is shown in the Table $\mathbf{1 .}$

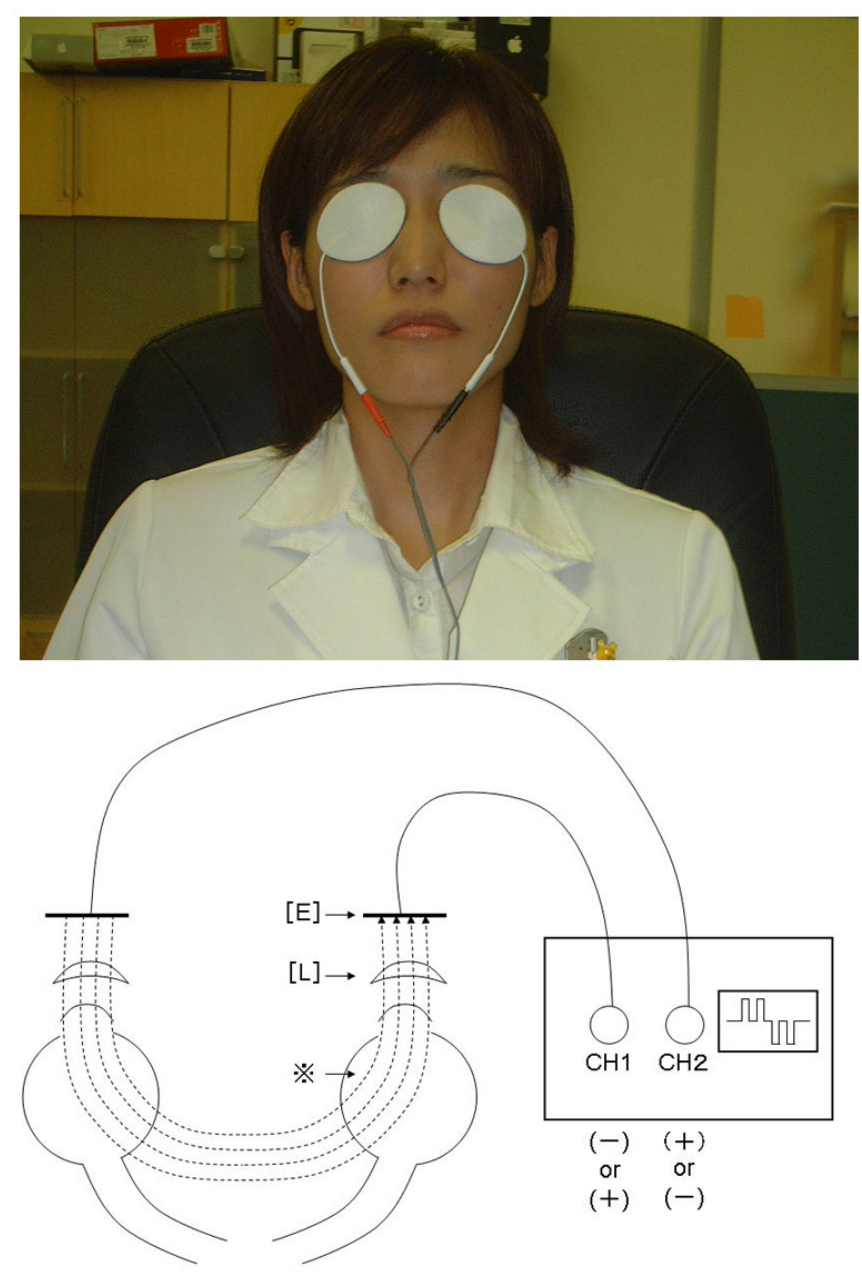

Fig. (1). Top: Appearance of the transcutaneous electrical retinal stimulation therapy. Top: The skin electrodes are applied to patches on both eyelids and the microcurrent runs through them. The patient remains seated during the 20-minute treatment. Bottom: The schema of the transcutaneous electrical retinal stimulation therapy. The $[\mathrm{L}]$ indicates eyelid. The [E] indicates cutaneous contact electrode. *: The dotted lines show the electrical current which is regulated in a symmetric bidirectional way.

Table 1. Snellen Visual Acuity

\begin{tabular}{|c|c|c|}
\hline & $\begin{array}{c}\text { Wet-Type } \\
\text { ARMD }^{1}\left(n^{2}=27\right)\end{array}$ & $\begin{array}{c}\text { Dry-Type } \\
\text { ARMD }(n=7)\end{array}$ \\
\hline Pre-treatment & $\begin{array}{c}\text { C.F. }{ }^{3}-20 / 25 \\
20 / 400\end{array}$ & $\begin{array}{c}20 / 1000-20 / 50 \\
20 / 160\end{array}$ \\
\hline Post-treatment & $\begin{array}{c}20 / 100-20 / 32 \\
20 / 400\end{array}$ & $\begin{array}{c}20 / 100-20 / 40 \\
20 / 200\end{array}$ \\
\hline
\end{tabular}

Data are shown as range (median).

${ }^{1} \mathrm{ARMD}=$ age-related macular degeneration

${ }^{2} \mathrm{n}=$ number of eyes, ${ }^{3} \mathrm{C} . \mathrm{F}=$ counting fingers.

Although the improvement of visual acuity did not reach statistical significance in the entire group, the average of the ETDRS scores significantly improved from $29.5 \pm 5.1$ to $31.8 \pm 5.0$ (mean \pm SE, $P=0.0407$, paired t-test, Fig. ( 2 top), Table 2) in Group-W and from $39.8 \pm 4.7$ to $42.9 \pm 4.9$ in 
Group-D ( $P=0.0401$, paired t-test, Fig. (2 top), Table 2 ). The averaged mean deviation of the automated perimetry in Group-W was $-13.3 \pm 3.1 \mathrm{~dB}$ before treatment and $-12.4 \pm 3.1$ $\mathrm{dB}$ after treatment (mean $\pm \mathrm{SE}, P=0.0247$, paired t-test, Fig. ( 2 bottom), Table 2). However, in Group-D, no significant improvement was shown; from $-9.3 \pm 3.2 \mathrm{~dB}$ to $-9.3 \pm 2.8 \mathrm{~dB}$ $(P>0.05$, paired t-test, Fig. (2 bottom), Table 2).

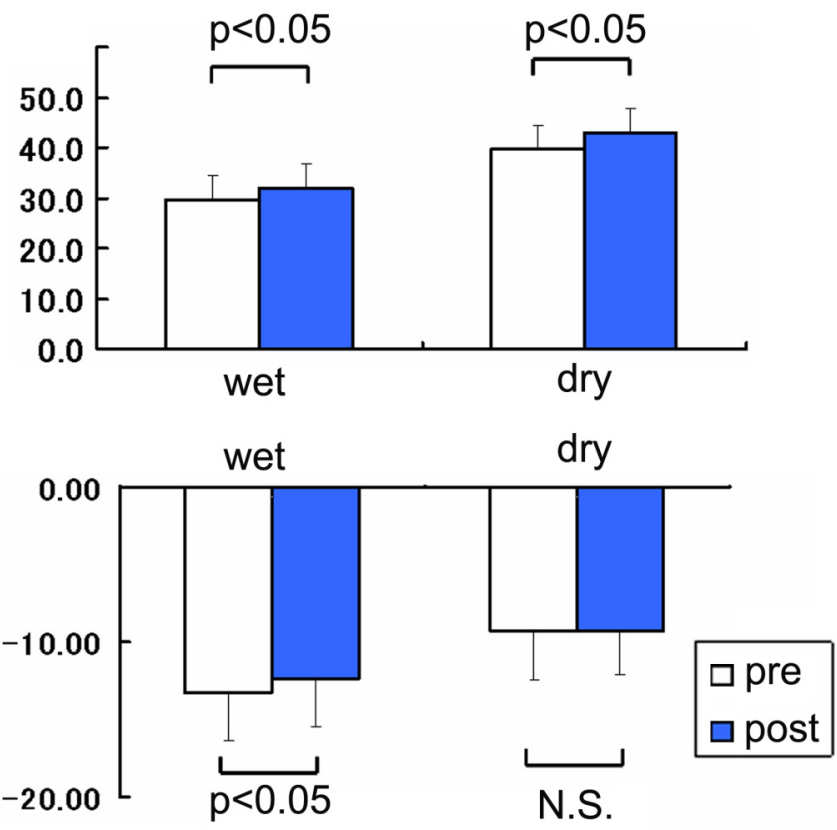

Fig. (2). Changes in visual function after the microcurrent therapy at 4 weeks. Top: The averaged Early Treatment Diabetic Retinopathy Study (ETDRS) visual acuity score significantly improved from $29.5 \pm 5.1$ to $31.8 \pm 5.0$ (mean \pm SE, $P=0.0407)$ in wet-type age-related macular degeneration (ARMD) patients and in dry-type ARMD patients (from $39.8 \pm 4.7$ to $42.9 \pm 4.9, P=0.0401$ ). Bottom: The averaged mean deviation of the automated perimetry improved from $13.3 \pm 3.1 \mathrm{~dB}$ to $-12.4 \pm 3.1 \mathrm{~dB}$ after treatment (mean $\pm \mathrm{SE}, P=0.0247$ ) in wet-type ARMD patients while in dry-type ARMD patients, it changed from $-9.3 \pm 3.2 \mathrm{~dB}$ to $-9.3 \pm 2.8 \mathrm{~dB}(P>0.05)$. The 'N.S.' indicates 'not significant'.

The subjective score in each group is shown in Fig. (3). Generally patients were satisfied and preferred to continue the treatment. However, it showed no significant correlation with the other parameters, such as visual acuity and the averaged mean deviation. No obvious change was observed either by slit-lamp or funduscopy. No ocular and systemic complications were observed except one patient who developed contact dermatitis on both superior lids. We decided to stop treatment, considering the adverse side effect to be serious, despite the 62-year-old man's strong preference to continue the treatment and instead initiated treatment using ofloxacin ointment.

\section{CONCLUSIONS}

A number of trials have been performed to develop an effective way to control the progression and complications of ARMD, but it remains limited [2-7]. This is attributed to the lack of understanding of the pathogenesis and final irreversible damage of the neural network including photoreceptor cells. Recently, subretinal implants were reported to have a
Table 2. ETDRS Score and Mean Deviation

\begin{tabular}{|c|c|c|c|c|c|c|c|c|}
\hline \multirow{2}{*}{ Case } & \multirow{2}{*}{ Gender } & \multirow{2}{*}{ Age } & \multirow{2}{*}{ Laterality } & \multirow{2}{*}{ Type } & \multicolumn{2}{|c|}{ ETDRS Score } & \multicolumn{2}{|c|}{$\begin{array}{c}\text { Mean } \\
\text { Deviation }\end{array}$} \\
\hline & & & & & $\begin{array}{l}\text { Pre } \\
\text { Tx }\end{array}$ & $\begin{array}{l}\text { Post } \\
\text { Tx }\end{array}$ & $\begin{array}{l}\text { Pre } \\
\text { Tx }\end{array}$ & $\begin{array}{l}\text { Post } \\
\text { Tx }\end{array}$ \\
\hline 1 & M & 83 & $\mathrm{~L}$ & W & 36 & 46 & -6.30 & -7.36 \\
\hline \multirow{2}{*}{2} & \multirow{2}{*}{ M } & \multirow{2}{*}{71} & $\mathrm{R}$ & W & 79 & 77 & -6.71 & -1.44 \\
\hline & & & $\mathrm{L}$ & W & 18 & 21 & -11.22 & -7.18 \\
\hline \multirow{2}{*}{3} & \multirow{2}{*}{ M } & \multirow{2}{*}{75} & $\mathrm{R}$ & W & 33 & 37 & -17.93 & -14.86 \\
\hline & & & $\mathrm{L}$ & W & 5 & 8 & -21.48 & -18.09 \\
\hline \multirow{2}{*}{4} & \multirow{2}{*}{ M } & \multirow{2}{*}{81} & $\mathrm{R}$ & W & 1 & 2 & -18.69 & -21.54 \\
\hline & & & $\mathrm{L}$ & W & 50 & 52 & -1.98 & -3.22 \\
\hline 5 & $\mathrm{M}$ & 71 & $\mathrm{~L}$ & W & 19 & 22 & -10.54 & -9.63 \\
\hline \multirow{2}{*}{6} & \multirow{2}{*}{ M } & \multirow{2}{*}{62} & $\mathrm{R}$ & W & 62 & 64 & -4.34 & -2.77 \\
\hline & & & $\mathrm{L}$ & W & 57 & 65 & -8.50 & -8.32 \\
\hline 7 & M & 51 & $\mathrm{R}$ & W & 43 & 54 & -4.61 & -5.29 \\
\hline \multirow{2}{*}{8} & \multirow{2}{*}{ M } & \multirow{2}{*}{68} & $\mathrm{R}$ & W & 72 & 67 & -4.37 & -2.64 \\
\hline & & & $\mathrm{L}$ & W & 26 & 21 & -3.42 & -6.23 \\
\hline 9 & M & 85 & $\mathrm{R}$ & W & 0 & 4 & -28.94 & -27.76 \\
\hline \multirow{2}{*}{10} & \multirow{2}{*}{ M } & \multirow{2}{*}{57} & $\mathrm{R}$ & W & 70 & 65 & -4.89 & -4.32 \\
\hline & & & $\mathrm{L}$ & W & 41 & 39 & -4.00 & -4.63 \\
\hline \multirow{2}{*}{11} & \multirow{2}{*}{ M } & 72 & $\mathrm{R}$ & W & 3 & 8 & -29.56 & -27.27 \\
\hline & & 12 & $\mathrm{~L}$ & W & 0 & 4 & -30.03 & -28.33 \\
\hline 12 & M & 84 & $\mathrm{~L}$ & W & 19 & 18 & -11.13 & -8.07 \\
\hline 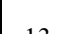 & $\Gamma$ & & $\mathrm{R}$ & W & 15 & 18 & -29.34 & -28.09 \\
\hline 15 & $\Gamma$ & 19 & L & W & 0 & 1 & -28.96 & -29.02 \\
\hline 14 & $M$ & 77 & $\mathrm{R}$ & W & 17 & 23 & -10.29 & -9.22 \\
\hline 14 & 101 & 11 & L & W & 1 & 20 & -12.75 & -14.04 \\
\hline 15 & $M$ & 70 & $\mathrm{R}$ & W & 3 & 2 & -25.22 & -26.03 \\
\hline 15 & IVI & 19 & $\mathrm{~L}$ & W & 9 & 6 & -15.18 & -13.45 \\
\hline 16 & $M$ & 70 & $\mathrm{R}$ & W & 45 & 48 & -4.45 & -3.61 \\
\hline 10 & $1 \mathrm{VI}$ & 10 & $\mathrm{~L}$ & W & 72 & 66 & -3.50 & -1.55 \\
\hline 1 & $\mathrm{M}$ & 71 & $\mathrm{R}$ & D & 26 & 31 & -2.84 & -3.57 \\
\hline 2 & $\mathrm{M}$ & 84 & $\mathrm{R}$ & D & 68 & 71 & -3.71 & -9.46 \\
\hline 3 & M & 85 & $\mathrm{~L}$ & D & 39 & 42 & -13.02 & -9.63 \\
\hline & & & $\mathrm{R}$ & D & 7 & 5 & -25.57 & -23.46 \\
\hline 4 & $\mathrm{M}$ & 10 & $\mathrm{~L}$ & D & 35 & 35 & -18.96 & -14.26 \\
\hline 6 & & & $\mathrm{R}$ & D & 36 & 42 & -1.47 & -2.43 \\
\hline J & 101 & . & L & D & 68 & 74 & 0.58 & -2.36 \\
\hline
\end{tabular}

M: male; F: female; R: right: L: left; W: wet type; D: dry type; mean deviation is shown as value (dB); ETDRS: Early Treatment Diabetic Retinopathy Study.

protective effect on the remaining retinal neurons, possibly by means of upregulating neurotrophic factors [19,23,24]. Consequently, the electrical stimulation of the retinal circuit might have a potential neuroprotective effect on the degenerating retina. Survival of photoreceptors following transcorneal electrical stimulation was reported in Royal College of Surgeons' rats [31]. Therefore, we performed a pilot study to 


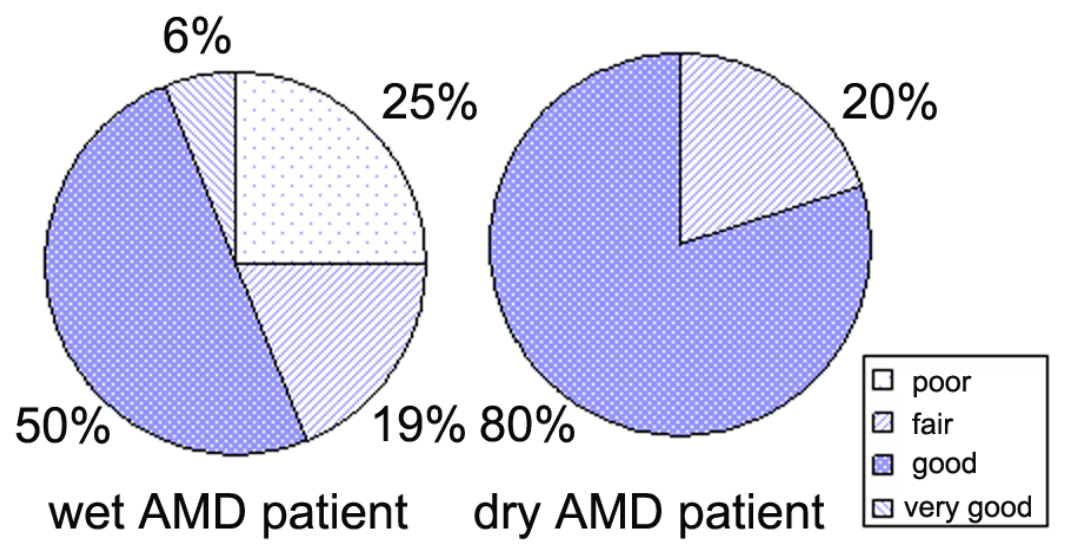

Fig. (3). Subjective score in wet and dry-type age-related macular degeneration patients. Patients rated (poor, fair, good, and very good as 1 , 2,3 , and 4 , respectively) their subjective visual function change 4 weeks after treatment. The score showed no significant correlation with the other parameters such as visual acuity or the averaged mean deviation.

investigate a therapeutic effect of electrical retinal stimulation on the degenerating retina. A novel treatment, transcorneal electrical stimulation, invented by Morimoto et al. [20] showed dramatic advancement compared with subretinal implantation of an electrical device. However, that procedure is invasive, especially on the cornea, and requires clinical treatment. The current study shows a less invasive way that can be performed by the patient himself even at home.

In the $1960 \mathrm{~s}$, a number of investigators reported clinical application of electrical retinal stimulation for evaluating retinal function, but not for treatment [25-28]. In such investigations, normally the electrical stimulation was provided using a corneal contact lens and no severe adverse effects were reported. As expected, in the current study, serious adverse effects, such as severe vision loss or corneal erosion, were not seen. One case among a total of 23 cases $(4.3 \%)$ developed contact dermatitis, which should be considered an inherent complication of the therapy. In this case, it was not severe, treatment was stopped and the application of ofloxacin ointment led to immediate disappearance of the dermatitis. Such complications might be avoided by using a different material for attaching the skin electrodes. Since this is an almost completely new treatment, it would be necessary for clinicians to be reminded that there might be some other unknown potential hazard.

Our results demonstrated that the microcurrent retinal stimulation has the potential of improving retinal function of the wet-type ARMD, although these are preliminary results and the study's weaknesses limit the generalization of the findings: small number of patients studied, relatively short follow-up times, and absence of a control group. Therefore, the findings from this study cannot be interpreted as justifying the definite efficacy of the microcurrent therapy for ARMD. The information and data obtained from this study are, however, useful in that they bring to light the future possibility of novel alternative treatment for a refractory agerelated eye disease. In the present study, the wet-ARMD seemed to benefit, whereas the dry-AMD did not in terms of visual field parameter. It is speculated that the photoreceptor cell and/or RPE cell, which benefits this therapy, should be freshly or mildly damaged, and that relative acute damage in wet-type ARMD could be recovered. Further investigation of larger numbers and a longer observation period designed as a randomized control trial and also basic research will be necessary to determine the feasibility of the therapy, and to understand the therapeutic role of the microcurrent on the progressively degenerating photoreceptors.

\section{REFERENCES}

[1] Klein R, Klein BE, Tomany SC, Meuer SM, Huang GH. Ten-year incidence and progression of age-related maculopathy: The Beaver Dam eye study. Ophthalmology 2002; 109: 1767-79.

[2] Treatment of age-related macular degeneration with photodynamic therapy (TAP) Study Group. Photodynamic therapy of subfoveal choroidal neovascularization in age-related macular degeneration with verteporfin: one-year results of 2 randomized clinical trials-TAP report. Arch Ophthalmol 1999; 117: 1329-45. Erratum in: Arch Ophthalmol 2000; 118: 488.

[3] Verteporfin In Photodynamic Therapy Study Group. Verteporfin therapy of subfoveal choroidal neovascularization in age-related macular degeneration: two-year results of a randomized clinical trial including lesions with occult with no classic choroidal neovascularization--verteporfin in photodynamic therapy report 2. Am J Ophthalmol 2001; 131: 541-60.

[4] Bessler NM, Vam Study Writing Committee. Verteporfin therapy in age-related macular degeneration (VAM): an open-label multicenter photodynamic therapy study of 4,435 patients. Retina 2004 ; 24: 512-20. Erratum in: Retina 2004; 24: 990.

[5] Veen JCCMi', Beekman AJ, Bel EH, Sterk PJ. Recurrent exacerbations in severe asthma are associated with enhanced airway closure during stable episodes. Am J Respir Crit Care Med 2000; 161(6): 1902-6.

[6] Visudyne in Minimally Classic Choroidal Neovascularization Study Group. Verteporfin therapy of subfoveal minimally classic choroidal neovascularization in age-related macular degeneration: 2-year results of a randomized clinical trial. Arch Ophthalmol 2005; 123: 448-57.

[7] Slakter JS, Stur M. Quality of life in patients with age-related macular degeneration: impact of the condition and benefits of treatment. Surv Ophthalmol 2005; 50: 263-73.

[8] Andreoli CM, Miller JW. Ranibizumab in neovascular age-related macular degeneration. Clin Interv Aging 2006; 1: 451-66.

[9] Pieramici DJ, Rabena MD. Anti-VEGF therapy: comparison of current and future agents. Eye 2008; May 23. [Epub ahead of print].

[10] Age-Related Eye Disease Study Research Group. Risk factors for the incidence of Advanced Age-Related Macular Degeneration in the Age-Related Eye Disease Study (AREDS) AREDS report no. 19. Ophthalmology 2005; 112: 533-39.

[11] AREDS Research Group. Associations of mortality with ocular disorders and an intervention of high-dose antioxidants and zinc in the Age-Related Eye Disease Study: AREDS Report No. 13. Arch Ophthalmol 2004; 122: 716-26.

[12] Age-Related Eye Disease Study Research Group. The effect of five-year zinc supplementation on serum zinc, serum cholesterol and hematocrit in persons randomly assigned to treatment group in 
the age-related eye disease study: AREDS Report No. 7. J Nutr 2002; 132: 697-702.

[13] Age-Related Eye Disease Study Research Group. A randomized, placebo-controlled, clinical trial of high-dose supplementation with vitamins $\mathrm{C}$ and $\mathrm{E}$ and beta carotene for age-related cataract and vision loss: AREDS report no. 9. Arch Ophthalmol 2001; 119: 143952.

[14] Age-Related Eye Disease Study Research Group. A randomized, placebo-controlled, clinical trial of high-dose supplementation with vitamins $\mathrm{C}$ and $\mathrm{E}$, beta carotene, and zinc for age-related macular degeneration and vision loss: AREDS report no. 8. Arch Ophthalmol 2001; 119: 1417-36.

[15] Klein RJ, Zeiss C, Chew EY, et al. Complement factor H polymorphism in age-related macular degeneration. Science 2005; 308: 385-9.

[16] Edwards AO, Ritter R III, Abel KJ, Manning A, Panhuysen C, Farrer LA. Complement factor $\mathrm{H}$ polymorphism and age-related macular degeneration. Science 2005; 308: 421-4.

[17] Haines JL, Hauser MA, Schmidt S, et al. Complement factor $\mathrm{H}$ variant increases the risk of age-related macular degeneration. Science 2005; 308: 419-21.

[18] Morimoto T, Miyoshi T, Fujikado T, Tano Y, Fukuda Y. Electrical stimulation enhances the survival of axotomized retinal ganglion cells in vivo. Neuroreport 2002; 13: 227-230.

[19] Chow AY, Chow VY, Packo KH, Pollack JS, Peyman GA, Schuchard R. The artificial silicon retina microchip for the treatment of vision loss from retinitis pigmentosa. Arch Ophthalmol 2004; 122: 460-9.

[20] Morimoto T, Miyoshi T, Matsuda S, Tano Y, Fujikado T. Transcorneal electrical stimulation rescues axotomized retinal ganglion cells by activating endogenous retinal IGF-1 system. Invest Ophthalmol Vis Sci 2005; 46: 2147-55.

[21] Nibuya M, Morinobu S, Duman RS. Regulation of BDNF and trkB mRNA in rat brain by chronic electroconvulsive seizure and antidepressant drug treatments. J Neurosci 1995; 15: 7539-47.
[22] Al-Majed AA, Brushart TM, Gordon T. Electrical stimulation accelerates and increases expression of BDNF and trkB mRNA in regenerating rat femoral motoneurons. Eur J Neurosci 2000; 12: 4381-90.

[23] Pardue MT, Phillips MJ, Yin H, et al. Neuroprotective effect of subretinal implants in the RCS rat. Invest Ophthalmol Vis Sci 2005; 46: 674-82.

[24] Pardue MT, Phillips MJ, Yin H, et al. Possible sources of neuroprotection following subretinal silicon chip implantation in RCS rats. J Neural Eng 2005; 2: S39-47.

[25] Potts AM, Inoue J, Buffum D. The electrically evoked response of the visual system (EER). Invest Ophthalmol 1968; 7: 269-78.

[26] Miyake Y, Yanagida K, Yagasaki K. Clinical application of EER (electrically evoked response). (1) Analysis of EER in normal subjects (author's translation) Nippon Ganka Gakkai Zasshi 1980; 84: 354-60.

[27] Miyake Y, Yanagida K, Yagasaki K. Clinical application of EER (electrically evoked response) (2) Analysis of EER in patients with dysfunctional rod or cone visual pathway (author's translation) Nippon Ganka Gakkai Zasshi 1980; 84: 502-9.

[28] Shimazu K, Miyake Y, Watanabe S. Retinal ganglion cell response properties in the transcorneal electrically evoked response of the visual system. Vision Res 1999; 39: 2251-60.

[29] Fujikado T, Morimoto T, Matsushita K, Shimojo H, Okawa Y, Tano Y. Effect of transcorneal electrical stimulation in patients with nonarteritic ischemic optic neuropathy or traumatic optic neuropathy. Jpn J Ophthalmol 2006; 50: 266-73.

[30] Holladay JT. Visual acuity measurements. J Cataract Refract Surg 2004; 30: 287-90.

[31] Morimoto T, Fujikado T, Choi JS, et al. Transcorneal electrical stimulation promotes the survival of photoreceptors and preserves retinal function in royal college of surgeons rats. Invest Ophthalmol Vis Sci 2007; 48: 4725-32. 